\title{
Research on eggshell structure and quality: An historical overview
}

\section{Author(s)}

Hunton $\mathrm{P}^{1}$

Past President, World's Poultry Science Association

\section{Mail Address}

Peter Hunton

RR\#4, Stn. Galt,

Cambridge, ON

N1R 5S5, Canada

E-mail phunton@sympatico.ca

\section{Keywords}

Calcium, eggshell, eggshell proteins, shell structure.

\section{ABSTRACT}

The eggshell is an important structure for two reasons. Firstly it forms an embryonic chamber for the developing chick, providing mechanical protection and a controlled gas exchange medium. Secondly it is a container for the market egg, providing protection of the contents and a unique package for a valuable food.

The superficial structure of the shell has been known for over 100 years. The shell consists of $97 \%$ calcium carbonate, and this is provided to the hen in the diet. However, the chemical must be broken down in the digestive system and then re-synthesized in the shell gland to form the shell. This results in a turnover of blood Ca of $\sim 100$ times each 24 hours.

Provision of calcium to layers has been researched at length, but the key work, conducted at Cornell University in the 1960's, showed the necessity for sources with large particle size, for example, oyster shells. Subsequent research has defined guidelines that, if correctly followed, will yield reliable and optimum eggshell quality.

Breakage or cracking of eggshells in market channels is a serious concern. Cracks result from a combination of shell strength and integrity, and the extent of the "insult" received by the egg during handling. Measurement of shell strength, and assessment of "insults" is important to the poultry industry.

Most recent research has identified the ultra-structure of the shell, with resulting opportunities for industrial remedies, and possible new selection criteria, to ensure maximum shell quality throughout the egg industry.

\section{INTRODUCTION}

Why is the eggshell such an important component of the egg? Consumers throw it away. It is very "costly" for the hen to produce. Breeders and managers spend many hours working to ensure that nothing goes wrong with it.

The hen's (or turkey's) egg is firstly, a unique package designed as a complete system of reproduction. Once a fertilized gamete, located on the yolk surface, is surrounded by albumen and shell, all that is needed to produce a chick or poult is the right temperature and humidity, and turning. The broody hen can provide all these facilities, although we now use artificial incubation in the commercial industry. But the eggshell is crucial, because it protects the embryo from mechanical damage, and regulates gas exchange between the developing embryo and the external environment. It also prevents contamination by bacteria and other pathogens, of a very vulnerable organism. Finally, the eggshell provides a source of nutrients, primarily calcium, to the developing embryo. 
In the commercial egg industry, the eggshell provides a perfect package for an important food item. As for the embryo, the shell provides protection from mechanical damage and from contamination of the contents, so that the egg reaches the consumer free of bacteria, viruses and other pathogens.

Failure of the shell for any reason compromises the egg's value, whether as a hatching egg or food product. Egg producers have to be aware of these factors because the economic consequences of shell failures are significant. By the time the shell is formed on the egg, all of the investment of nutrients has been made, and death of the embryo, or the loss of nutritional value, represents potentially a total loss to the farmer.

This review will consider some of the more applied factors affecting the production of the eggshell, and some of the methods used to evaluate it in various situations. It will also consider some of the recent discoveries with respect to its structure, that may be utilized in future improvements.

\section{Eggshell macro-structure and composition}

The gross structure of the eggshell has been known for more than a century. The Dutch scientist von Nathusius published analyses of the shells of various birds in 1881 and 1882 (see Romanoff and Romanoff, 1949) and they show much the same picture as publications from the $20^{\text {th }}$ century (Figures 1 and 2).

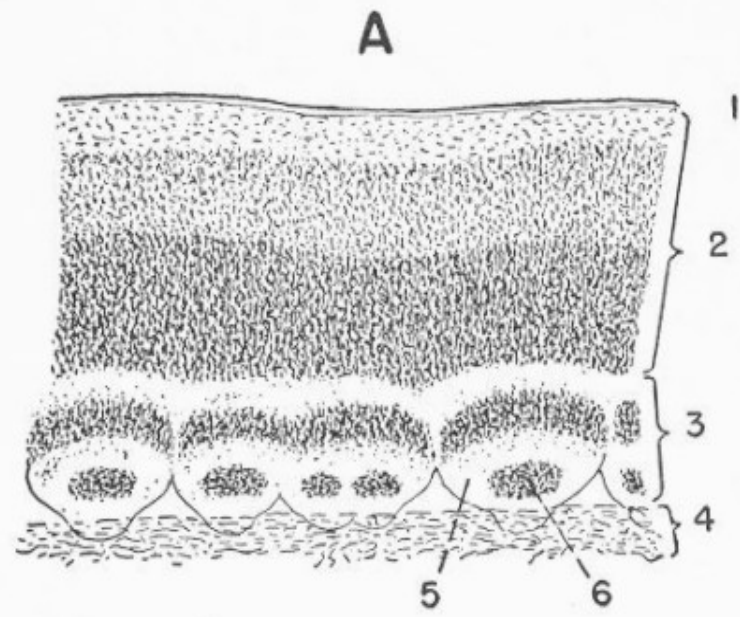

Figure 1 - Egg shell section (from Romanov and Romanov, 1949).

Beginning on the surface of the albumen, the shell membranes, of which there are two, provide the foundation of the shell. On the surface of the outer membrane, mamillary knobs form as the first stage of shell formation, and from these, the main layer of the shell, called the palisade layer, develops. A thin outer layer, called the cuticle, completes the shell. Figure 3 shows the sequential deposition of the parts of the shell (from Nys, quoted by Hincke, 2002). Further excellent and detailed descriptions are given by Solomon (1991).

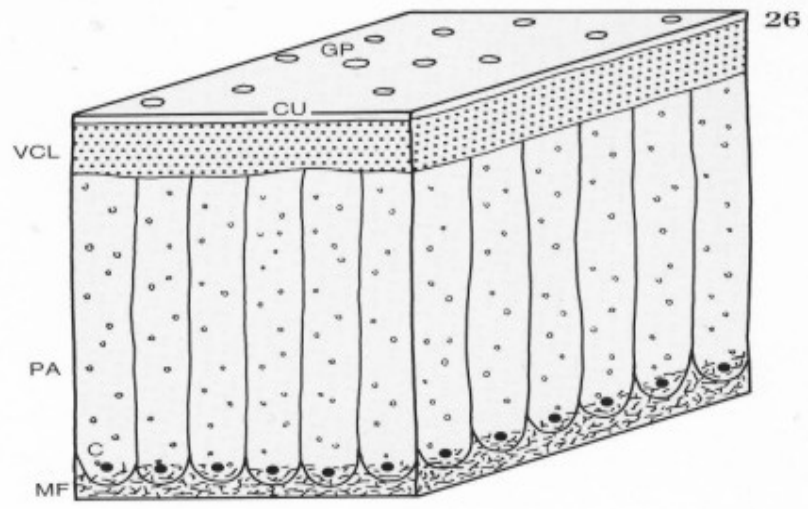

Figure 2 - Eggshell structure as illustrated by Solomon, 1990.

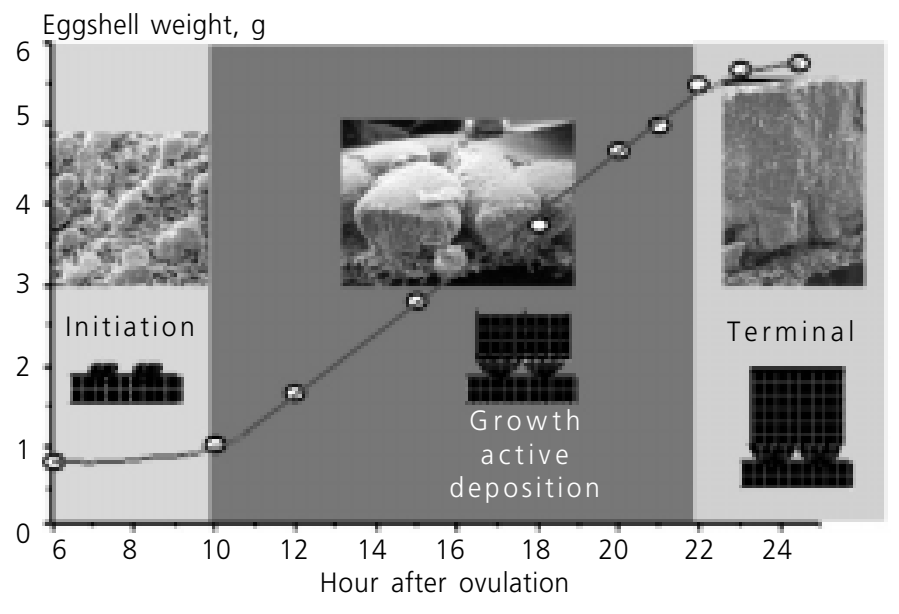

Figure 3 - Kinetics of eggshell calcification. (Courtesy of Dr. Max Hincke, Univ. of Ottawa).

Very early in the study of the shell, chemical analyses showed that it is composed of about $97 \%$ calcium carbonate, (Burley and Vadehra, 1989) and most of the research on shell quality concentrated on this fact. This is because calcium has to be provided as part of the hens' diet, while the carbonate portion is produced internally during the normal course of metabolism. The dietary ingredient normally used to provide calcium to the laying hen is usually calcium carbonate, the same chemical as the shell. However, this feed ingredient is broken down into its components in the intestine, and 
the calcium is absorbed into the blood stream. It is then either stored in the bones until needed for shell formation, or transported directly to the shell gland for synthesis into eggshell calcium carbonate. Shell formation is by far the most lengthy process in egg formation. Once the ovum, with the germ cell attached, is released from the ovary, it takes roughly 4-6 hours to lay down the albumen, and 18-20 hours to lay down the membranes and shell.

A few numbers may help to illustrate this miracle. The blood volume of the average $1.5 \mathrm{~kg}$ layer is about $75 \mathrm{ml}$. The maximum calcium concentration is about $30 \mathrm{mg} / 100 \mathrm{ml}$, so the maximum calcium content at any one time might be $25 \mathrm{mg}$. The calcium in the shell of a $60 \mathrm{~g}$ egg weighs $\sim 2.3 \mathrm{~g}$, or 92 times the blood content. So the calcium turnover to produce the eggshell could easily be 100 times, or five times per hour, in the period during which the shell is produced. [For a detailed explanation of calcium logistics in the laying hen, see Etches, 1987].

Another way of looking at this is that in the course of a full laying cycle, today's $1.5 \mathrm{~kg}$ white egg layer may lay 320 eggs, of $60 \mathrm{~g}$ average weight, for a total of $19.2 \mathrm{~kg}$. Shells are about $10 \%$ of the egg weight, so there is $1.92 \mathrm{~kg}$ of eggshell, or more than the hen's body weight laid down in the course of one year's production.

\section{Getting the calcium to the laying hen}

Until the late 1960's most of the calcium was provided to layers as finely ground limestone. This was cheap to buy, and easily incorporated into layer feeds. At this time, the hens laid at least $15 \%$ less than today's flocks. But even then, producers were beginning to experience shell quality problems. In the 1960's, Scott and colleagues at Cornell University showed that calcium carbonate supplied in the form of oyster shells was more effective than the same amount of calcium from finely ground limestone (Scott et al., 1971). The reason for this was that the larger particles of the oyster shells took longer to digest, and more was absorbed into the blood stream than from the limestone. Subsequent research showed that hens would seek out oyster shells or large calcium particles late in the day, prior to the most rapid period of shell formation (which mostly occurs during the night, when feed is not consumed) and thus provide themselves with a continuous supply of calcium when it was most needed.

These experiments have been repeated many times, with all kinds of variations. Roland, from Auburn
University, has conducted much of this research. This is reviewed in Roland and Bryant (2000). Earlier work is reviewed by Roland (1986 a and b).

Roland shows that there is nothing complex about maintaining maximum shell quality if a few simple rules are followed.

\section{Feed calcium levels appropriate for laying} hens a minimum of $7 \mathrm{~d}$ prior to first egg.

Rather than specify the calcium level in the diet, formulate to ensure the specific daily calcium intake required based on feed intake and egg mass output.

Provide at least $25 \%$ and up to $100 \%$ of the calcium supplement in large particle form. Minimum particle size considered large is $2 \mathrm{~mm}$, and particles up to 5 $\mathrm{mm}$ are acceptable. When particle size is optimized, oyster shell has no advantage over limestone.

Ensure that the limestone is highly soluble and not contaminated with other compounds.

\section{Measurement of eggshell strength and quality}

If the mineral content of the shell is so constant, what else can influence quality, and thereby the main commercial concern, the number of cracked eggs found when table eggs are graded? The strength of the shell has been a major preoccupation of scientists for most of the past half-century. A multitude of methods have been investigated to measure or estimate eggshell strength. The challenge here is to somehow predict how many eggs would be cracked in industrial conditions. This is hard when we are faced with measuring individual eggs. There is an assumption that genetics plays a part in eggshell quality, and breeders have been among those most involved in applied research in this area. Making the link between what can be measured and selected at the primary breeding level and the eventual outcome in a commercial egg production environment has been a huge challenge. Among the traits breeders have utilized as selection criteria are:

- Egg specific gravity, an index of shell thickness

- Breaking strength - the actual force required to fracture the shell

- Shell deformation under a fixed load (usually 0.5 or $1.0 \mathrm{~kg}$ )

Many other traits have been investigated and used as quality criteria in eggshell research. These include:

- Shell weight

- \% Shell 
- Weight of shell/unit of surface area

- Shell thickness

- Beta-particle backscatter

- Ultrasound wave reflection

All of these are valuable measurements in assessing eggshell quality, but all share the same shortcomings. They are measured on individual eggs, while industrial requirement is to minimize the number of eggs broken between the times they are laid and when they reach the consumer. These and other methods to measure eggshell characteristics have been reviewed by Hunton (1987and 1995).

In recent years, a new generation of measurement techniques has become available to assess or predict eggshell strength or quality. One such method, called dynamic stiffness, has been described by De Baerdemaeker et al. (2003), and others are under study.

The missing link here is that in order to be broken, the egg must be exposed to an environmental insult that has nothing to do with its composition, structure or quality. Carter (1970) stated, "The eggshell will crack if the strength of the shell is less than the strength of the environmental insult to which it is exposed." In order to investigate problems of eggshell breakage in industry, we must look at the insults as well as the eggshells. This concept has been enormously helpful in identifying the causes of increased undergrade eggs in commercial situations. However, this is outside the boundaries of this review.

\section{Understanding the micro-structure of the eggshell}

When the scanning electron microscope became widely available to the scientific community, it was natural that it would be used to investigate the structure of the eggshell in greater detail than was previously possible. The first to do this was Simons (1971), from the Netherlands, in the course of studies for his Ph.D. degree. Perhaps the most important finding was the complexity of the structure of the shell. Rather than simple layers of crystals of calcium carbonate, the shell was shown to consist of a very complex type of mineral formation, with a protein matrix as its foundation.

In the mid-1980's Solomon and colleagues at the University of Glasgow, Scotland, began to conduct further studies of the fine structure of the eggshell. They identified a variety of abnormalities which resulted in weakening of the structure, and a risk of crack formation. These were well described and illustrated in Solomon's book, "Egg and Eggshell Quality," published in 1991.

While the shell faults can be described and identified, they do not lend themselves to use as selection criteria for breeders because they are qualitative rather than quantitative. However, they have been used to point to environmental problems and disease incidence.

These investigations also highlighted the importance of the proteins forming the shell matrix, and attracted a number of other researchers into the field. In 1994, Hincke, from the University of Ottawa, announced the identification of the first protein unique to the eggshell, Ovocleidin 17. Since then, Hincke has, in association with a number of other scientists in France, Spain and elsewhere, identified several more proteins which are important components of the eggshell's structure (see Mann et al., 2003 and Hincke et al., 2003). They have also demonstrated the effects of the presence of proteins on the type of crystalline structure that occurs, as shown in Figure 4. It has long been known that the presence of proteins in solutions influences crystalline structure, and this could be an additional tool in the hands of breeders seeking new ways to improve shell structure. Hincke and associates have also studied the distribution of the various proteins in different parts of the shell, and some of their results are shown in Figure 5. In addition to the proteins themselves, genes coding for them are being studied, and this too may be useful in future attempts to breed for better shell structure.

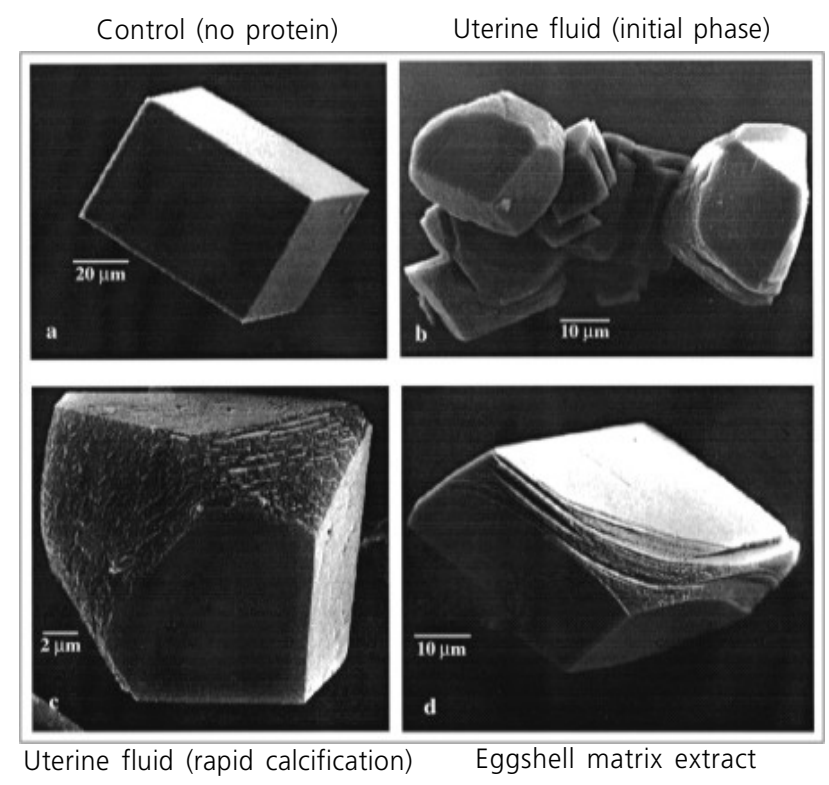

Figure 4 - Calcite crystalization is altered by matrix proteins. (Courtesy of Dr. Max Hincke, Univ. of Ottawa). 


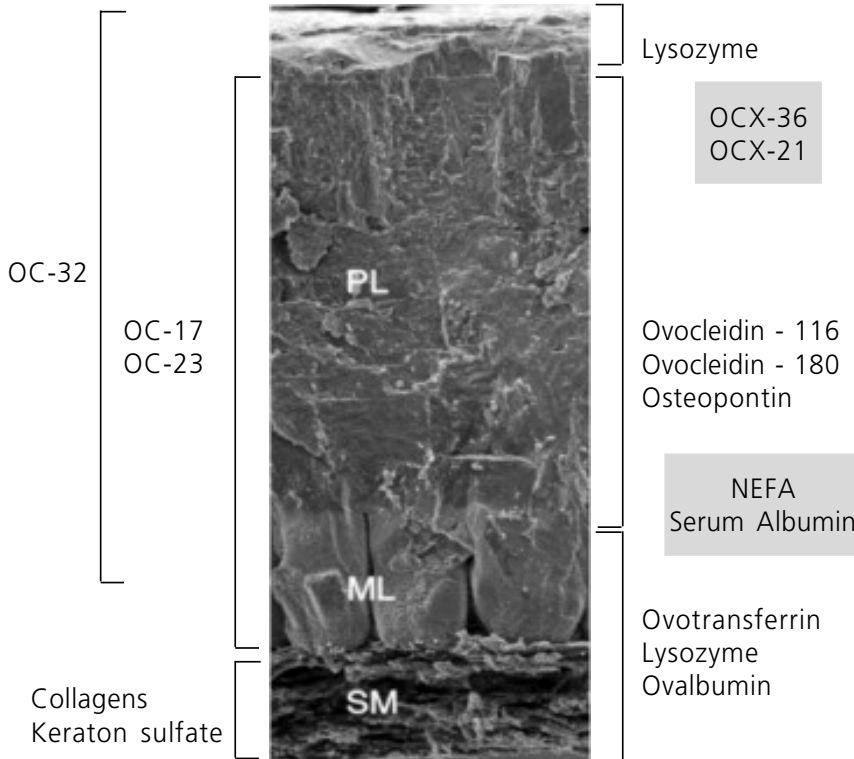

Figure 5 - Distribution of eggsheel proteins. (Courtesy of Dr. Max Hincke, Univ. of Ottawa).

Changes in the proteins with age, and with other factors affecting eggshell structure, have also been demonstrated. Nys et al. (1999) have reviewed much of this information.

These studies are ongoing, and several of them are being conducted in cooperation with major primary breeders. It is hoped that this cooperation may yield knowledge of specific proteins that are unique to certain individuals or families within the foundation lines used for breeding egg layers. Selection of these families would enable breeders to improve shell quality in subsequent generations. However, this must always be done with the acceptance that the primary function of the shell, from the hen's perspective, is to protect and nurture an embryo. The value of the shell in the market table egg is one imposed by the human population.

\section{References}

Burley RW \& Vadehra DV. The Avian Egg; Chemistry and Biology. John Wiley \& Sons. NY. 1989

Carter TC. Why do egg shells crack? World's Poultry Science Journal, 1970. 26(2):549-561.
De Baerdemaeker J, Bamelis F, Kemps B, Govaerts T, Decuypere E and De Ketalaere B. Non-destructive measurements of egg quality. 2003. Proceedings X European Symposium on the Quality of Eggs and Egg Products. 840-853. St. Brieuc, France.

Etches RJ. Calcium logistics in the laying hen. Proc. 69 $9^{\text {th }}$ Annual Meeting, Federation of American Societies for Experimental Biology, Anaheim, CA. pp 619-628, 1987.

Hincke MT. Unraveling Shell Structure for Future Improvements in Eggshell Quality. Presentation to Ontario Egg Producers' Annual Meeting. 2002.

Hincke MT, Guest S, Gautron J \& Nys Y. Proceedings X European Symposium on the Quality of Eggs and Egg Products. 783-790. St. Brieuc, France. 2003.

Hunton P. Laboratory evaluations of egg quality. in Egg Quality Current Problems and Recent Advances. Ed. R.G. Wells and C.G. Belyavin. Butterworths 1987.

Hunton P. Understanding the architecture of the egg shell. World's Poultry Science Journal, 1995; 51:141-148

Mann K, Gautron J, Hincke MT, McKee MD, Schneider WJ. and \& Nys Y. Clusterin is an egg white and egg shell protein. 2003. Proceedings $X$ European Symposium on the Quality of Eggs and Egg Products. 771-782. St. Brieuc, France. 2003.

Nys $Y$, Hincke MT, Arias JL, Garcia-Ruiz JM \& Solomon SE. Avian Eggshell Mineralization. Poultry. Avian Biology Reviews. 1999; 10: 143-166.

Roland DA Egg Shell Quality III. Calcium and phosphorus requirement of commercial leghorns. World' Poultry Science Journal, 1986a; 42:154-165

Roland DA. Egg Shell Quality IV. Oyster shell versus limestone and the importance of particle size or solubility of calcium source. World's Poultry Science Journal. 1986b.; 42:166-171.

Roland DA \& Bryant M. Nutrition and Feeding for Optimum Egg Shell Quality. Proc. XXI World's Poultry Congress, Montreal (CD Rom) 2000.

Romanoff AL \& Romanoff AJ. The Avian Egg. John Wiley \& Sons, NY. 1949

Scott ML, Hull SJ \& Mullendorf PA. The calcium requirements of laying hens and effects of dietary oyster shell upon egg shell quality. Poultry Science. 1971; 50:1055-1063

Simons PCM. Ultrastructure of the hen eggshell and its physiological interpretation. Ph.D thesis. Communication \#175. Het Spelderholt, Beekbergen, The Netherlands. 1971.

Solomon SE. Egg and Eggshell Quality. Wolfe Publishing, Aylesbury, England. 1991. 